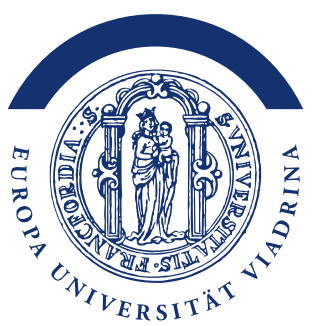

\title{
Borders in Motion: \\ An application related to the video game Animal Crossing: New Horizons
}

Behailu Shiferaw Benti

Georg Stadtmann

European University Viadrina Frankfurt (Oder)

Department of Business Administration and Economics

Discussion Paper No. 423

March 2021

ISSN 18600921 


\title{
Borders in Motion: An application related to the video game Animal Crossing: New Horizons
}

\author{
Behailu Shiferaw Benti ${ }^{a *}$ and Georg Stadtmann ${ }^{b}$
}

March 2021

\begin{abstract}
In 2020, the video game Animal Crossing: New Horizons was listed among the top ten in terms of revenue. We analyze the game by relying on an interdisciplinary framework of border studies. Borders can be interpreted not only in a geographical sense but also in terms of a temporal dimension as well as a cultural dimension. We highlight how the game blurs the borders between the real and virtual world.
\end{abstract}

Keywords: Border, Animal Crossing, real versus virtual world

a* Corresponding author: Behailu Shiferaw Benti, European University Viadrina, Economics and Economic Theory, Grosse Scharrnstr. 59, 15230 Frankfurt (Oder), Germany. Germany, Tel.: +49 03355534 2703, E-Mail: Benti@europa-uni.de

${ }^{b}$ Georg Stadtmann, European University Viadrina, Economics and Economic Theory, Grosse Scharrnstr. 59, 15230 Frankfurt (Oder), Germany. Tel.: +49 03355534 2700, E-Mail: stadtmann@europa-uni.de and University of Southern Denmark, Odense. 


\section{Contents}

\begin{tabular}{lll}
\hline & Introduction & 1
\end{tabular}

2 ACNH: Description \& classification 2

2.1 Game description . . . . . . . . . . . . . . . 2

2.2 Game classification . . . . . . . . . . . . . . . . . . 3

3 Borders in Motion: Description of the concept 3

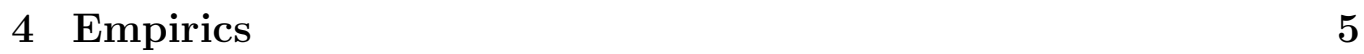

4.1 Fashion, models, \& influencers . . . . . . . . . . . . . . . 5

4.2 Politics . . . . . . . . . . . . . . . . . . . . . . . . . . . 7

4.3 The Bank of Nook \& the interest rate cut . . . . . . . . . . . 8

4.4 Museums move into the virtual world . . . . . . . . . . . . . . 10

$\begin{array}{lll}5 & \text { Conclusions } & 10\end{array}$

\section{List of Figures}

$1 \quad$ Durability, Permeability, Liminality . . . . . . . . . . . . . . . 17

2 Joe Biden's ACNH campaign . . . . . . . . . . . . 17

\section{List of Tables}

$1 \quad$ Framework: State and types of borders . . . . . . . . . . 18 


\section{Introduction}

In 2020, several countermeasures were implemented during the Corona pandemic. These measures reduced and limited the space for real life activities and defined new borders for the real world. In some countries, measures as drastic as 'stay at home orders' were established ${ }^{1}$ Stay at home requirements define the borders and reduce the permeability between, for example, the home and the outside world $2^{2}$ Within Maslow's hierarchy of needs (Maslow 1943), the impact of the pandemic on basic and psychological needs is evident: the Covid crisis reduced security and safety, which resulted in slips from the second level hierarchy. Factors such job loss, fear of being infected, the social pressure from preventive instructions, less frequent contacts with family and friends, are all causing changes and psychological challenges.

The effect on overall economic activity has been negative (IMF 2020). There has been a tremendous negative impact on, for example, the aviation \& tourism sector. However, not all industries have suffered: online businesses such as Amazon, Zoom, and Netflix have been able to expand. Also the video game ${ }^{3}$ industry profited from the fact that schools, work, and leisure activities have been restricted (Needleman 2020a).

In March 2020, at the peak of the first Corona lockdown, a newly released game Animal Crossing: New Horizon (ACNH) took the market by storm. ${ }^{4}$ Zhu (2020) explores the psychology behind the video game and explains that it provides a dreamland for players to temporarily escape from cruel reality, and there is a risk of becoming lost in escapism. However, the virtual world

\footnotetext{
${ }^{1}$ The Oxford Stringency Index provides information about the measures taken by various countries, using eight dimensions: 1. School closures 2. Workplace closures 3. Cancellation of public events 4. Restrictions on gatherings 5. Closing public transport 6. Stay at home requirements 7. Restrictions on internal movements 8. International travel control. See Dreger \& Gros (2021, p. 173) for a description of the index and an application related to US unemployment data on a US State level.

${ }^{2}$ With special permission, people might be allowed to go grocery shopping or visit a doctor - so that not only the borders but also the orders are in motion. We will define and elaborate the 'orders in motion' in Section 3.

${ }^{3}$ See Bergonse (2017) and Arjoranta (2019) for definitions of video games.

${ }^{4}$ With total revenues of $\$ 654$ million, it is ranked seventh out of the top ten 'premium games' of 2020 (SuperData 2021).
} 
can also be regarded as a perfect social platform which allows maintaining social interactions with others to get rid of loneliness.

The work of Zhu (2020) already highlights the distinction between the real world and the virtual world. In this paper, we analyze $A C N H$ from the perspective of border studies. We apply an interdisciplinary heuristic (Schiffauer et al. 2018), which has the following two dimensions:

- The 'state of the border': its durability, permeability, and liminality.

- The 'types of borders': geographical, time, social.

This paper is structured as follows: Section 2 describes the game and Section 3 the theoretical framework. Empirical results are derived in Section 4 . The last section concludes.

\section{ACNH: Description \& classification}

\subsection{Game description}

ACNH is a game launched in 2020 for the Nintendo Switch console. This open-ended game is of the adventure, puzzle, and life simulation genre. In-game time is synchronized with the real world. After the players embark on a desert island with animal inhabitants, they have the freedom to set their own goals to complete in-game activities. Without any form of competition, players engage in activities such as interacting with the inhabitants, fishing, planting trees, collecting bugs, and designing \& building houses. The game has a creative platform where collected resources can be crafted into items such as useful tools, clothing, and furniture. In addition, the players decorate their island and houses (Nintendo 2020a).

'Nook Inc.' is an in-game development company that helps players in day-to-day activities. Business transactions are possible in the game, where players can buy items and sell their collections to Nook's store for Bells (the in-game currency). Interaction with other players and sharing experiences is possible. Players can visit other islands and also invite other players to 
theirs. Invitations can be sent to an in-game 'best friend list' or through a 'Dodo Code' to whomever is interested (Animal Crossing Wiki 2021).

\subsection{Game classification}

To some extent, the desert island could be interpreted as an homage to Daniel Defoe's novel Robinson Crusoe. However, the narrative form can be better described as a comic or fable. The fable seems to be the most appropriate since one never knows whether the avatar displays an animal, a human, or a hermaphrodite being. Due to the reduced complexity of the graphics, Ihring (2020) describes the game as a "toddler version of 'Second Life' or 'Sims'."

\section{Borders in Motion: Description of the con- cept}

Table 1 contains the heuristic which will be applied in this paper. Analytical dimension 1 (horizontal) represents the state of the borders. Analytical dimension 2 (vertical) reflects the types of borders.

Durability deals with the forms and consequences of the establishment of borders, their dissolution, and their possible reconstitution. Within this state, the following aspects are examined: how are borders actively established, how are inside-outside relations constituted, and asymmetries installed and maintained? What consequences do the dissolutions of a border have? (Schiffauer et al. 2018, p. 18).

- Insert Table 1 about here -

Permeability treats, for example, how the fine regulation of borders takes place. Which persons, objects, and information cross a border, which do not? How are decisions made about the selection of persons, objects, and information to cross the border and those to be denied? How is the policing of the border implemented in practice - and how do attempts to regulate 
the border in turn produce forms of subversion? (Schiffauer et al. 2018, p. 19).

Liminality can best be defined as an overlapping era or area where borders do not strictly separate two spaces. These in-between spaces and gray areas are central to the understanding of the problem of boundaries, because in them, transitions from one order to another are prepared, implemented, and mastered. In these spaces, the orientation and control function of borders is partially or completely suspended. They are therefore spaces in which the potential for innovation creates the possibility of 'new space' as well as the possibility of anomie and the loss of meaning. The investigation of in-between spaces, gray zones, transitional phases, and hemlines is more suitable than any other to make the creation of order and meaning by borders recognizable in their simultaneously orienting and disciplining effect (Schiffauer et al. 2018, pp. 19-20).

Figure 1 illustrates the three main states of a border. This triadic distinction is an analytical and heuristic one: in practice, all three states regularly occur in combination with each other, but with different weights (Schiffauer et al. 2018, p. 13) $!^{5}$

- Insert Figure 1 about here -

It is also very important to stress that borders in this way are not just 'there', but are actively produced anew and differently in performative practices of border drawing. The practices of drawing boundaries thereby run counter to the practices of dissolving boundaries (Schiffauer et al. 2018, p. 13). This implies that not only the borders are in motion but also the orders can change over time. Within one society, borders are established, defended, transformed, and destroyed by the government (legislative, executive, and

\footnotetext{
${ }^{5}$ Other studies, such as Milgram \& Kishino (1994), have examined the real and virtual world by the use of a virtuality continuum: the two corners to the left and right are labeled real and virtual environment. Located between these two extremes are the areas labeled augmented reality and augmented virtuality.
} 
judiciary), other organizations (for example, the media. ${ }^{6}$ NGOs), and also individuals. In case that these forces change the border, we label this phenomenon that orders are in motion.

\section{Empirics}

\subsection{Fashion, models, \& influencers}

The gamification of fashion has established strong interconnections between the users of the game, and fashion companies as well as (graphic) designers, models, and photographers. Fashion is designed by either the gamers themselve: $5^{7}$ or the fashion companies (Gucci, MCM) which upload part of their collection to the game. For example, MCM digitized a $\$ 495$ jacquard skirt and a $\$ 750$ velour track jacket, among other items from its fall and winter 2020 collection. This kind of virtual outfit can be regarded as a status symbol: unfortunately, "I can't quite afford Gucci right now," one gamer explained (Tran 2020). Social borders that are still existent in the real world become permeable in the virtual world. In the real world, luxury fashion is regarded as one of the 'esteem needs' of Maslow's hierarchy of needs (Maslow 1943).

Scott (2021) describes the most recent developments in the evolution of fashion and avatars: in the first part of the Covid crisis, brands promoted their lines on digital runways: elite fashion brands used avatars to showcase their real world designs. Afterwards, the avatar and digital goods market began to grow. "Now, we're seeing an influx of apparel brands presenting similar digital collections as before, BUT the apparel on display can be purchased both for human and avatar. The circle is complete and the

\footnotetext{
${ }^{6}$ Bigl \& Schlegelmilch (2020) analyzed reports on video games in main news programs of German television channels. The study indicated that $48 \%$ of game players in Germany are women. However, in the media coverage of video games, the report protagonists are predominantly men. This reflected the role of media in stereotyping the dominance of male players and undermining the representation of femininity within games.

7 "Fans want to be part of the artistic process." The founder and creative director of the company which invented the dating simulation game Monster Prom said fans have crafted hundreds of themes, including one inspired by drag queens (Tran 2020). This is also related to a business model pattern called Outside-In: Ideas from the outside are systematically screened in order to develop own-products (Osterwalder \& Pigneur 2010).
} 
paradigm has changed."

Customization options available in $\mathrm{ACNH}$ allowed players to recreate notable real world designer pieces for their own characters. An Instagram account @animalcrossingfashionarchive having 50k followers had started archiving some of the finest customized designs from players. The famous Swedish based global payments and shopping platform Klarna decided to collaborate by making a virtual pop-up shop after selecting ten top designs from the page (Ferere 2020). Another popular Instagram account @nookstreetmarket provides designs that resemble some real life garments (Ihring 2020, Tan 2020).

Marketers for Gillette Venus had the idea to pronounce the personality of an avatar and to make the look more unique. Gilette created a custom line of 264 designs, reflecting 19 skin and body types in 8 tones, including acne, cellulite, and prosthetic legs (Tran 2020). In modern society, uniqueness has received much emphasis and attention. For example, Reckwitz (2020) talks about the Society of Singularities in order to analyze the transition processes and conflicts in post-industrial society. Especially, he describes contemporary society as a system of evaluation that distinguishes particularity and uniqueness.

In the marketing literature, Gillette's marketing campaign serves as a good example for individual marketing. This terms refers to tailoring products and marketing programs to the needs and preferences of individual customers 8

\footnotetext{
${ }^{8}$ This is also called one-to-one marketing, customized marketing, markets-of-one marketing, and micro marketing.
} 


\subsection{Politics}

The 'Hong Kong pro-democracy' protest 9 had taken its cause to ACNH. This sparked a reaction from the Chinese government in the form of removing the game from E-commerce platforms in China. Although this was not announced officially, the Chinese government sent a message to sellers on the Alibaba-owned Taobao. Since the game is completely banned, people opted for imported consoles from the gray market (Wallace 2020).

During the US presidential election campaign, Senator Biden tried to capitalize on the game's popularity by launching a virtual field office for voters and designing downloadable yard signs that could be used by game players (Taylor \& Ortiz 2020, Kelly 2020). Figure 2 gives an impression of the yard signs. Also, the Democratic Representative Ocasio-Cortez followed this trend when she visited supporters' islands (Nagumo 2020). The game is a good example of a two sided platform 10 On the one side, the huge numbers of players and their involvement makes ACNH interesting for Biden's campaign. On the other side, the addition of yard signs also helps gamers to decorate their gardens and to express their political standpoint. Both sides profit from the existence of each other (Osterwalder \& Pigneur 2010).

\section{- Insert Figure 2 about here -}

\footnotetext{
${ }^{9}$ Another example where the Hong Kong protests influenced the world of video games is how in 2019, the game developer Blizzard Entertainment banned one sports player from a tournament held for the game Hearthstone. The player showed support of the Hong Kong protests during a live streaming interview. The player was banned for one year from any tournament and the contracts of two employees involved were terminated. The general public, other sports players, and also former and active employees of Blizzard reacted with a boycott movement. A letter from Congressional representatives (US) prompted Blizzard to reduce the punishment. Some claim the ban was a way to maintain Blizzard's relationship with the Chinese government and its partial owner Tencent, a Chinese technology giant. Later on the ban was reduced to six months after Blizzard claimed that its relationship with China had not influenced its initial decisions (Wikipedia 2021).

${ }^{10} \mathrm{~A}$ two-sided platform combines two sides of a market. One side attracts users: the price is frequently set to zero in order to attract the largest customer base possible. Therefore, this strategy is also referred to as 'Free,' as a business model. The other side of the platform charges positive prices and the 'large customer base' is sold to advertisers. For example, Google allows the public to use its search engine free of charge but sells its customer base to companies, which pay for advertisements (Osterwalder \& Pigneur 2010, p. 92).
} 
While some Trump supporters created "MAGA" caps to express their political standpoint, a Trump campaign deputy countered Biden's initiative in his very own way: "This explains everything: Joe Biden thinks he's campaigning for president of 'Animal Crossing' from his basement [... The Trump campaign will continue to spend its resources campaigning in the real world with real Americans." Pesce (2020).

Activists from Hong Kong spread messages in ACNH, which led the game to be then banned in China 11 This reflects a spillover from the virtual world to the real world. The ban has also resulted in the growth of transactions in the gray market. These factors imply a permeability of borders. In addition, following the virtual election campaigns, in November 2020, Nintendo (2020b) released a guideline for business and organizations that persuades them to refrain from 'bringing politics into the game' (Webster 2020).

The release of this guideline from Nintendo and also the reaction of the Chinese government underline that not only borders but also orders are in motion: the rules are adjusted by Nintendo to avoid any actions that might be regarded as damaging the reputation of Nintendo or having a bad influence on the ACNH community.

\subsection{The Bank of Nook \& the interest rate cut}

In $A C N H$, players can deposit their virtual currency (Bells) with the Bank of Nook in order to earn interest. In April 2020, the interest rate was reduced from $0.5 \%$ to $0.05 \%$. Some players argued that this interest rate cut mirrored the monetary policy of central banks in the real world, which also reduced their rates due to the Covid-19 shock (Lewis \& Wigglesworth 2020). In the above mentioned framework, this is an example of a semi-permeability between the real and virtual world in the social dimension.

\footnotetext{
${ }^{11}$ Jiang \& Fung (2019) mentioned that digital entertainments in China has become part of everyday life. However, in response to globalization, China has adopted neotechno-nationalism by making defensive and reactionary policy decisions towards globally imported cultural products such as video games. These strategies are mainly aimed at protecting economic and political benefits.
} 
Other market observers interpreted the cut as a measure of the game developer Nintendo to discourage the attractiveness of time travelling: previously, players had been manipulating their game console to travel well ahead in time in order to acquire a huge amount of interest on their deposits (Lewis \& Wigglesworth 2020) ${ }^{12}$ Time travelling is an example of a permeability of a border in the time dimension. The reaction of Nintendo can also be interpreted in a way that not only the borders, but also the orders are in motion: Rules are adjusted in order to strengthen the durability of the border.

In order to compensate for this negative shock on income, players discussed various alternatives: one alternative source of income could stem from searching for tarantulas. The spiders appear relatively seldom and only during the evening or at night. After a catch, a spider can be sold for 8,000 Bells. This activity is relatively time-consuming and dangerous, since a bite causes the avatar to faint 13 Another alternative source of income is an investment in turnips. Turnips are sold to players only on Sundays during a specific time period for prices between 90 and 100 Bells. For the next week, turnips can be resold to other players or shops. Prices vary during the week within a range of 15-800 Bells (Nelson 2020). This investment is risky since the turnips' price varies during the week and they rot on Sundays, so that they become worthless (Thier 2020).

Therefore, it becomes clear that the interest rate cut of the Bank of Nook changed the incentive structure and thereby the behavior of the players. Especially, it changed the risk attitude of the players, who engaged in riskier behavior 14 The borders between markets and activities became unstable. In

\footnotetext{
${ }^{12}$ In order to avoid having gamers travel even farther into the future, Nintendo enacted another measure: from April 2020 onwards, the maximum amount of savings was capped at 9,999 bells (Lewis \& Wigglesworth 2020).

${ }^{13}$ Another alternative to generate revenue is to go fishing and sell the catch afterwards. Van Ooijen (2018) analyzes the killability of animals in video games and raises ethical concerns. He demonstrates that fish are a prime example of a class of animals raising less moral concerns, even in supposedly ethical and animal friendly games.

${ }^{14}$ It is a well-known fact of economic theory that a change of one price changes the behavior of households and also has spillover effects on other markets. For example, in the portfolio balance model (Branson 1977), an expansionary monetary policy of the central
} 
the above mentioned framework, this would be an example of a durability in the social dimension.

\subsection{Museums move into the virtual world}

The Covid pandemic led to a lockdown of cultural life (concerts, cinemas, theaters). Museums as well had to close their real exhibitions in galleries, but the museums' online collections were, of course, still available to the public. The J. Paul Getty Museum took the chance and offered some ACNH users the possibility of transforming their paintings into their virtual world. "By letting users upload images free from their own legitimate digital collections, museums [are] seeking to remain relevant" (Crow 2020).

Some other museum followed this initiative, so that the virtual ANCH world nowadays hosts an in-game museum with several masterpieces. One official from the San Antonio Museum of Art explained: "At some point, artworks like these lived in somebody's home, so there's some nice symmetry there" (Crow 2020). This implies that art that once decorated the homes in real life, were afterwards displayed in real museums and later in their online collections. Nowadays, the masterpieces are back in peoples' homes-however, only in their virtual world. This is a good example of geographical borders and to some extent touches all three state dimensions.

\section{Conclusions}

Borders in Motion is a well established heuristic for analyzing interdisciplinary phenomena in the real world. We applied this framework to the virtual world of a video game. We showed that the borders are in motion in the three states (durability, permeability, and liminality) as well as in geographical, temporal, and social dimensions.

Additionally, we highlighted that also the orders are in motion, since the game developer actively changed game settings and rules in order to react bank makes, c.p., domestic and foreign bonds more attractive, increases demand, and affects asset prices. 
to the (mis-)behavior of the players.

In order to generalize our findings, one could broaden the scope and also apply it to other games. For example, in June 2020, Fortnite removed police cars from their game during a time period where there was a national debate in the US over law-enforcement practices in response to the killing of George Floyd (Needleman 2020b).

Therefore, future research could focus on other games or game genres. Furthermore, it could also be used to characterize the development of games and the gaming industry over time.

Conflict of interest: The corresponding author states that there is no conflict of interest. 


\section{References}

Animal Crossing Wiki (2021). https://animalcrossing.fandom.com/wi ki/Animal_Crossing_Wiki

Arjoranta, Jonne (2019). How to Define Games and Why We Need to. The Computer Games Journal, 8(3), 109-120. https://doi.org/10.100 7/s40869-019-00080-6

Bergonse, Rafaello (2017). Fifty Years on, What Exactly is a Videogame? An Essentialistic Definitional Approach. The Computer Games Journal, 6(4), 239-255. https://doi.org/10.1007/s40869-017-0045-4

Bigl, Benjamin, and Schlegelmilch, Christoph (20200). Are Video Games Still a Boys' Club? How German Public Television Covers Video Games. Games and Culture, 1555412020975637.

Branson, William H. (1977). Asset Markets and Relative Prices in Exchange Rate Determination. Socialwissenschaftliche Annalen, 1, 67-80.

Crow, Kelly (2020). Nintendo's 'Animal Crossing' Goes Upscale With Museum Masterpieces. The Wall Street Journal, August 19, 2020. https://www.wsj.com/articles/nintendos-animal-crossing-goe s-upscale-with-museum-masterpieces-11597852490

Dreger, Christian, and Gros, Daniel (2021). Lockdowns and the US unemployment crisis. Center for Economic Policy Research (CEPR) Covid Economics 64, January 13, 2021, 165-185. https://cepr.org/conte nt/covid-economics-vetted-and-real-time-papers-0

Ferere, Cassell (2020). How Luxury Streetwear Is Using Animal Crossing To Remain Digitally Accessible To Gen Z And Millennials. Forbes, August 30, 2020. https://www.forbes.com/sites/cassellferere /2020/08/30/luxury-streetwear-animal-crossing-digitallyaccessible/?sh=2222ca5675f7

Ihring, Silvia (2020). Im erfolgreichsten Nintendo-Spiel des Jahres geht es um Selbstverwirklichung. Die Welt-online Mai 24, 2020. https: 
//www.welt.de/icon/partnerschaft/article208153769/Animal-C rossing-Im-erfolgreichsten-Nintendo-Spiel-des-Jahres-geh t-es-um-Selbstverwirklichung.html?cid=onsite.onsitesearch

International Monetary Fund (IMF) (2020). World Economic Outlook Update, June $2020-=$ A Crisis Like No Other, An Uncertain Recovery. https://www.imf .org/en/Publications/WEO/Issues/2020/06/24/ WEOUpdate June2020

Jiang, Qiaolei, and Fung, Anthony YH (2019). Games with a continuum: Globalization, regionalization, and the nation-state in the development of China's online game industry. Games and Culture, 14(7-8), 801-824.

Kelly, Makena (2020). Biden campaign launches official Animal Crossing: New Horizons yard signs. The Verge, September 1, 2020. https: //www.theverge.com/2020/9/1/21409727/biden-harris-animal-c rossing-campaign-new-horizons-yard-signs-election

Lewis, Leo, and Wigglesworth, Robin (2020). Virtual rate cut forces Nintendo gamers into riskier assets. Financial Times, April 28, 2020. https://www.ft.com/content/68f96d24-02f0-42fd-b132-aba 0acba777f

Maslow, Abraham Harold (1943). A theory of human motivation. Psychological Review 50(4), 370-396.

Milgram, Paul, and Kishino, Fumio (1994). A taxonomy of mixed reality visual displays. IEICE TRANSACTIONS on Information and Systems, 77(12), 1321-1329.

Nagumo, Jada (2020). Nintendo's Animal Crossing changes game of politics in US and Asia. Nikkei, September 2, 2020. https://asia.nikkei. com/Business/Media-Entertainment/Nintendo-s-Animal-Crossin g-changes-game-of-politics-in-US-and-Asia

Needleman, Sarah E. (2020a). From 'Fall Guys' to 'Among Us,' How America Turned to Videogames Under Lockdown. Wall Street Journal, October 31, 2020. https://www.wsj.com/articles/from-fall-guys- 
to-among-us-how-america-turned-to-videogames-under-lockd own-11604116815?mod=searchresults_pos6\&page=1

Needleman, Sarah E. (2020b). 'Fortnite' Removes Police Cars From Game - Change in video game comes amid national debate over lawenforcement practices. Wall Street Journal, June 21, 2020. https: //www.wsj.com/articles/fortnite-removes-police-cars-from -game-11592773204

Nelson, Alex (2020). Here's how the Stalk Market works in Animal Crossing New Horizons, and how to make Bells quick through the Turnip Exchange. The Scotsman, April 7, 2020. https://www.scotsman.com /read-this/heres-how-stalk-market-works-animal-crossingnew-horizons-and-how-make-bells-quick-through-turnip-exc hange-2531597

Nintendo (2020a). Animal Crossing: New Horizons Overview https://ww w.nintendolife.com/games/nintendo-switch/animal_crossing_n ew_horizons

Nintendo (2020b). Animal Crossing: New Horizons Usage Guidelines for Businesses and Organizations. November 19, 2020 https://www.nint endo.co.jp/animalcrossing_announcement/en/index.html

NOOK STREET MARKET @nook_st_market https://twitter.com/no ok_st_market

Osterwalder, Alexander, and Pigneur, Yves (2010). Business Model Generation. Wiley.

Pesce, Nicole Lyn (2020). Trump camp mocks Joe Biden for 'campaigning for president of "Animal Crossing" ' with virtual yard signs. MarketWatch, September 2, 2020. https://www.marketwatch.com/story/ trump-camp-mocks-joe-biden-for-campaigning-for-president -of-animal-crossing-with-virtual-yard-signs-2020-09-01

Reckwitz, Andreas (2020). Society of Singularities. John Wiley \& Sons. 
Schiffauer, Werner, Jochen Koch, Andreas Reckwitz, Kerstin Schoor, and Hannes Krämer (2018). Borders in Motion: Durabilität, Permeabilität, Liminalität. Working Paper Series B/ORDERS IN MOTION No. 1 https://opus4.kobv.de/opus4-euv/frontdoor/index/index/docI d/311

Scott, Doug (2021). Rise of the Avatars: Their Future in Gaming, Fashion and Music Our virtual selves are just getting warmed up. Subnation, February 1, 2021. https://musebycl.io/music/rise-avatars-the ir-future-gaming-fashion-and-music

SuperData (2021). 2020 Year in Review-Digital Games and Interactive Media.

Tan, Pakkee (2020). Gaming the fashion system: Nook Street Market is the collective taking over digital fashion. Vogue, September 21, 2020. https://vogue.sg/nook-street-market-instagram-animal-cro ssing-new-horizons/

Taylor, Derrick Bryson, and Ortiz, Aimee (2020). Biden Campaign Courts the Animal Crossing Island Vote With Yard Signs. New York Times, September 1, 2020. https://www.nytimes.com/2020/09/01/us/po litics/biden-animal-crossing.html

Thier, Dave (2020). How To Store Turnips In 'Animal Crossing: New Horizons'. Forbes, April 19, 2020. https://www.forbes.com/sites /davidthier/2020/04/19/how-to-store-turnips-in-animal-cr ossing-new-horizons/?sh=303653ca155b

Tran, Khanh T. L. (2020). Video games are the new runway. Coveted fashion brands are loving it. Los Angeles Times, December 4, 2020. https://www.latimes.com/lifestyle/story/2020-12-04/covid-1 9-fashion-brands-experiment-video-games

van Ooijen, E. (2018). The Killability of Fish in The Sims 3: Pets and Stardew Valley. The Computer Games Journal, 7(3), 173-180. https: //doi.org/10.1007/s40869-018-0055-x 
Wallace, Anthony (2020). Animal Crossing game removed from sale in China over Hong Kong democracy messages. The Guardian, April 14, 2020. https://www. theguardian.com/world/2020/apr/14/animal -crossing-game-removed-from-sale-in-china-over-hong-kong -democracy-messages

Webster, Andrew (2020). Nintendo asks brands to keep politics out of Animal Crossing. The Verge, November 19, 2020. https://www.thev erge.com/2020/11/19/21575052/nintendo-switch-animal-crossi ng-new-horizons-no-politics-allowed

Wikipedia (2021). Blitzchung controversy. https://en.wikipedia.org/w iki/Blitzchung_controversy

Zhu, Lin (2020). The psychology behind video games during COVID-19 pandemic: A case study of Animal Crossing: New Horizons. Human Behavior \& Emerging Technologies, 1-3. https://doi.org/10.1002/ hbe2.221 


\section{Appendix}

Figure 1: Durability, Permeability, Liminality
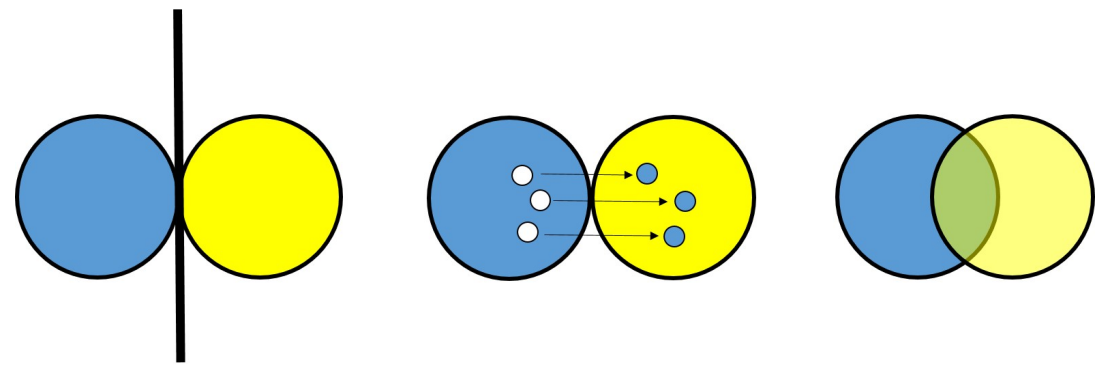

Source: Own representation.

Figure 2: Joe Biden's ACNH campaign

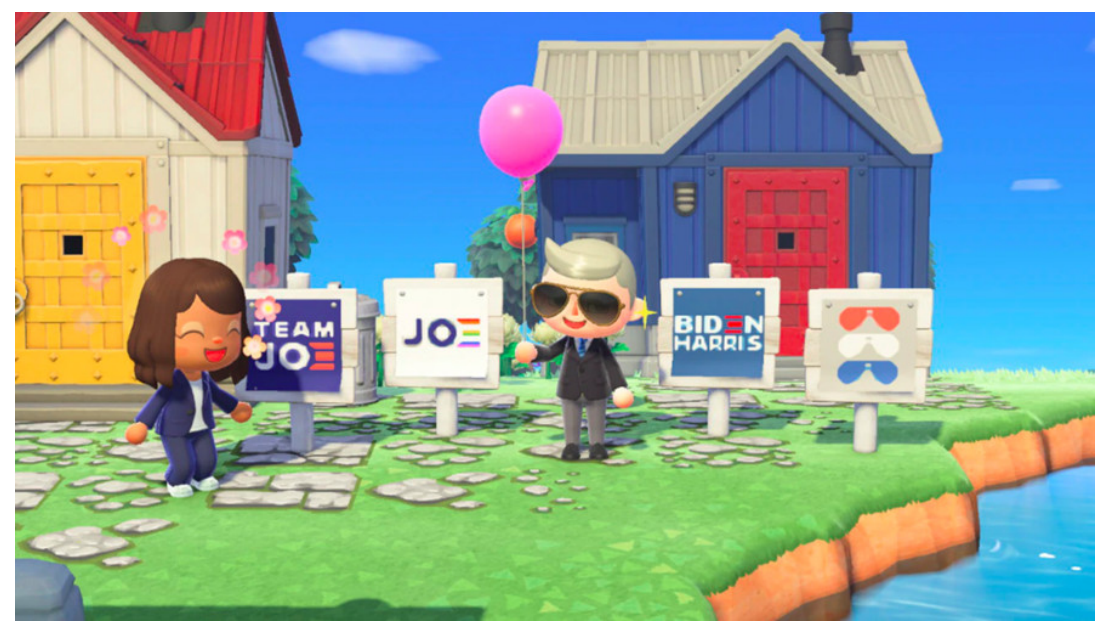

Source: Pesce (2020). 
Table 1: Framework: State and types of borders

\begin{tabular}{|l|l|c|c|c|}
\hline \hline \multirow{2}{*}{} & & \multicolumn{3}{|c|}{ State of the border } \\
\cline { 3 - 5 } & & Durability & Permeability & Liminality \\
\hline \multirow{2}{*}{$\begin{array}{l}\text { Types } \\
\text { of }\end{array}$} & geographical & 1 & 4 & 7 \\
\cline { 2 - 5 } borders & time & 2 & 5 & 8 \\
\cline { 2 - 5 } & social & 3 & 6 & 9 \\
\hline
\end{tabular}

Source: Schiffauer et al. (2018), pp. 16-18. 